\title{
Cytokine, Genotype, and Viral Load Profile in the Acute and Chronic Hepatitis B
}

\author{
Camilla Rodrigues de Almeida Ribeiro, ${ }^{1}$ Katrini Guidolini Martinelli, ${ }^{2}$ Vinícius da Motta de Mello, ${ }^{3}$ \\ Bruna da Silva Baptista, ${ }^{3}$ Natália Spitz Toledo Dias, ${ }^{1}$ lury Amancio Paiva, ${ }^{4}$ Lia Laura Lewis-Ximenez, ${ }^{3}$ \\ Luzia Maria de Oliveira Pinto, ${ }^{4}$ and Vanessa Salete de Paula ${ }^{1}$
}

\begin{abstract}
Several hepatitis B virus (HBV) factors, including viral load, genotype, genome mutations, and cytokine production, have been reported to be associated with different risks of progression of liver disease. The aim of this study was to verify if there is an association among the levels of cytokines (interleukin [IL]-35, IL-6, IL-17A, interferon [IFN]- $\gamma$ ) in the plasma, viral load, and the different genotypes of HBV in patients with acute or chronic hepatitis B. Methods: 49 serum samples, 20 from acute and 29 from chronic cases, were submitted to a real-time and nested-polymerase chain reaction to quantify, detect, and genotype HBV DNA. The cytokines IL-35, IL-6, IL-17A, and IFN- $\gamma$ were detected by an enzyme-linked immunosorbent assay (ELISA). The median viral load was $3.15 \log _{10} \mathrm{IU} \mathrm{DNA} / \mathrm{mL}$ and $2.90 \log _{10} \mathrm{IU} \mathrm{DNA} / \mathrm{mL}$ for acute and chronic patients, respectively. Genotype A, $\mathrm{D}, \mathrm{E}$, and $\mathrm{F}$ were identified in chronic carriers of $\mathrm{HBV}$ infection, while only genotype $\mathrm{A}$ and $\mathrm{F}$ were identified in individuals with acute infection. IFN- $\gamma(p=0.024)$ and IL-17A $(p=0.046)$ levels were significantly increased in chronic patients and IL-6 and IL-35 were higher in patients with acute infection, however, without statistical difference. IL-17A and IFN- $\gamma$ can be modulating proinflammatory effects and inducing hepatocellular damage, in chronic patients, and IL- 6 and IL-35 may be involved in viral elimination and protection against chronicity during the acute phase of infection. These results can contribute to understanding of the complex regulatory mechanisms of the host antiviral response related to cytokine production during acute and chronic HBV infection.
\end{abstract}

Keywords: hepatitis B, cytokines, immune response

\section{Introduction}

$\mathbf{H}^{\mathrm{s}}$ EPATITIS B VIRUS (HBV) AFFECTS 2 billion people worldwide (55). Of these, $\sim 257$ million persons, or $3.5 \%$ of the world population have a chronic infection with a risk of developing advanced liver disease, cirrhosis, and/or hepatocellular carcinoma, which cause 500 to 700 thousand deaths per year in the world $(28,55)$.

HBV belongs to the family Hepadnaviridae genus $O r$ thohepadnavirus $(23,34,50)$. Currently, HBV isolates are classified into 10 genotypes (A-J) and several subtypes, with a different geographic distribution $(16,31,47)$. The genotypes A, D, and F are predominant in Brazil $(27,37)$. Studies have shown that different genotypes and most of the subgenotypes have particular epidemiological and virological properties. In addition to the distinct geographical distribution, evidence suggests that genotypes are the result of
HBV biology (58), determining the course of the disease (41), and affecting the response to antiviral therapy (46).

The disease caused by the HBV can result in asymptomatic infection, acute self-limiting hepatitis, chronic hepatitis, or fulminant hepatitis, which can lead to cirrhosis or hepatocellular carcinoma (HCC) and in more severe cases requires liver transplantation. The degree of complication of chronic infection is closely associated with viral replication rate (28).

Serologic markers can be used to diagnose and distinguish between acute and chronic infections. Commercially available serological tests are used to detect HBV surface antigen (HBsAg), envelope antigen ( $\mathrm{HBeAg}$ ), HBV surface antibody (anti-HBs), HBV core antibody (anti-HBc), antibody of the HBV envelope (anti-HBe), and HBV DNA. The acute phase of HBV infection is characterized by the presence of surface antigen ( $\mathrm{HBsAg}$ ) in the serum, followed by the appearance of anti-HBc and total anti-HBc IgM. HBeAg

\footnotetext{
${ }^{1}$ Laboratory of Molecular Virology, Oswaldo Cruz Institute, Oswaldo Cruz Foundation, Rio de Janeiro, Brazil

${ }^{2}$ Department of Social Medicine, Espírito Santo Federal University, Espírito Santo, Brazil.

${ }^{3}$ Laboratory of Viral Hepatitis, Oswaldo Cruz Institute, Oswaldo Cruz Foundation, Rio de Janeiro, Brazil.

${ }^{4}$ Laboratory of Viral Immunology, Oswaldo Cruz Institute, Oswaldo Cruz Foundation, Rio de Janeiro, Brazil.
} 
is indicative of viral replication and infectivity and appears at the end of the incubation period and disappears shortly before the onset of $\mathrm{HBsAg}$ in the development of the symptomatic phase. It is a marker related to the presence of the viral genome $(1,18,48,52)$.

Approximately $5-10 \%$ of cases of infected adults and a significantly higher percentage of $\mathrm{HBV}$-infected infants and children develop a chronic infection characterized by continuous detectable expression of $\mathrm{HBsAg}$ for at least 6 months after the initial infection (26).

Chronic HBV infection comprises five different phases, they are the following: (1) chronic HBeAg-positive infection with normal alanine aminotransferase (ALT) (former immunotolerant phase), (2) chronic HBeAg-positive hepatitis with elevated ALT (former immunoreactive phase), (3) chronic HBeAg-negative infection with normal ALT (or inactive carrier), (4) HBeAg-negative chronic hepatitis with elevated ALT, and (5) HBsAg-negative phase (or hidden infection) (13).

Approximately two-thirds of the patients who seroconvert $\mathrm{HBeAg}$ to anti-HBe undergo a period of "flare" or reactivation defined as the abrupt increase in ALT in patients with chronic HBV. Reactivations can occur spontaneously several times in the same individual and do not necessarily result in seroconversion and can occur in $10 \%$ of $\mathrm{HBeAg}$ negative patients $(30,49)$.

The participation of adaptive immunity is essential for the viral elimination and termination of $\mathrm{HBV}$ infection. $\mathrm{CD} 4{ }^{+} \mathrm{T}$ lymphocytes activate $\mathrm{CD}^{+} \mathrm{T}$ lymphocytes (CTL) and promote differentiation of B lymphocytes (LB) into plasma cells for the production of antibodies $(6,35)$.

Cytokines represent a large family of molecules, including cytokines associated with Type 1 (Th1) T cell responses (e.g., interleukin-2 [IL-2], interferon [IFN- $\gamma]$ ), which have a functional contribution to immune responses; type 2 (Th2) $\mathrm{T}$ cell response (e.g., IL-4, IL-6, IL-10), which play a role in humoral immune responses; regulatory $\mathrm{T}$ cell-associated (Treg) cytokines with, for example, tumor growth factor beta (TGF- $\beta$ ) and IL-10, which are associated with immunomodulation and immunosuppression; and Type $17 \mathrm{~T}$ cell response (Th17) (e.g., IL-17, IL-22, IL-23), which play critical roles in mediating inflammation (22). Cytokines initiate downstream signaling pathway activities by binding to specific receptors expressed on target cells and play important roles in responses against viral infections (29).

As HBV is a noncytopathic virus, both HBV-related liver damage and viral control are immune-mediated. There is growing evidence that cytokine-mediated immune responses play an important role in determining clinical outcomes during $\mathrm{HBV}$ infection $(5,10,57)$.

The aim of this study was to verify if there are associations among the levels of cytokines (IL-35, IL-6, IL-17A, IFN- $\gamma$ ) in the plasma, viral load, and the genotypes with acute or chronic hepatitis B.

\section{Materials and Methods}

\section{Population studied}

This study was approved by the FIOCRUZ Research Ethics Committee with number CAAE 06109812.4.0000.5248. All patients in the study were aware of and according to their participation in the research, after signing the informed consent form, according to resolution number 466, of December
12, 2012 of the National Health Council-Ministry of Health of Brazil. Individuals coinfected with HIV and hepatitis, A, C, and $\mathrm{E}$ were excluded from the study. Socioepidemiological data, information about infection, HBV treatment, and risk behaviors were obtained from each patient record or from the questionnaire.

This study was a retrospective one, and the collection of samples was carried out between 2014 and 2017. A total of 49 individuals from National Reference Laboratory for Viral Hepatitis were included. This clinic serves as the National Reference Centre for Hepatitis Viruses in Brazil and receives persons suspected of having viral hepatitis, including acute and chronic cases and their contacts. The patients were divided in two different groups of infection: (1) 20 serum samples from acute hepatitis B patients and (2) 29 serum samples from chronic hepatitis B patients (without antiviral therapy). The inclusion criteria for the acute patients were the presence of HBsAg less than 6 months, anti-HBc IgM, HBeAg, and detection of HBV DNA and for the chronic patients, detection of HBsAg more than 6 months.

\section{Sample collection}

Peripheral blood samples were collected $(5 \mathrm{~mL})$ from each individual in a vacutainer tube (Becton Dickinson and Company, Franklin Lakes) containing sodium heparin $(20 \mathrm{~mL})$ to obtain plasma. After centrifugation, the plasma was separated and stored at $-70^{\circ}$.

\section{Biochemical tests}

Serum samples were subjected to biochemical doses of liver enzymes, such as aspartate aminotransferase; ALT; alkaline phosphatase; total, direct, and indirect bilirubin; and gamma-glutamyl transferase through a system of quantitative determination by photometry in kinetic mode using a commercial kit (LabMax 560; LabTest, Minas Gerais, Brazil) according to the manufacturer's instructions.

\section{Detection of HBV serological markers in serum samples}

To include the patients in the study, all samples were tested through enzyme immunoassays (EIA) for HBsAg (BioElisa HBsAg 3.0; BioKIT, Barcelona, Spain), anti-HBc IgM (BioElisa anti-HBc; BioKIT), anti-HBc IgM (ETI CORE IgMK Plus; DiaSorin, Saluggia, Italy), $\mathrm{HBeAg}$, and anti-HBe (e411 Cobas; Roche Diagnostics, Mannhein, Germany) according to the instructions from each manufacturer. AntiHAV IgM (DiaSorin), anti-HCV (Murex anti-HCV 4.0; DiaSorin), anti-HEV (BioKit), and Anti-HIV (DS-EIA-HIVAGAB-SCREEN, RPC, Diagnostic System, Berkshire, Russia) were used to exclusion screening.

\section{Molecular assay and phylogenetic analysis}

All samples positive to HBsAg were tested to HBV-DNA by nested polymerase chain reaction (PCR) and Abbott RealTime HBV kit (Abbott Laboratories). Extraction of HBV genetic material was performed according to the commercial kit (High Pure Viral Nucleic Acid Kit; Roche Diagnostics) for plasma samples. The pre-S/S genome region was amplified using a seminested PCR assay (51). 
Nested PCR products were loaded into a $1.5 \%$ agarose gel and stained with ethidium bromide to visualize the bands of an expected length of $1,200 \mathrm{bp}$. Amplicons obtained by nested PCR with an expected HBV size were purified using the High Pure PCR Product Purification Kit (Roche Diagnostics) according to the manufacturer's instructions. The sequence of the pre-S/S genes was determined from a single PCR fragment by using a BigDye Terminator Kit v3.1 (Applied Biosystems, Foster City, CA), and sequencing reactions were analyzed on an ABI3730xl automated sequencer (Applied Biosystems).

HBV genotyping was performed by phylogenetic analyses of the pre-S/S gene with HBV sequences representing all genotypes available in GenBank. Phylogenetic analysis was performed using the maximum likelihood method with the online version of the PhyML program (19). The reliability of the phylogenies was estimated with the approximate likelihood-ratio test (3) based on a Shimodaira-Hasegawalike procedure (SH-aLRT). The GenBank accession numbers for the HBV sequences obtained in this study are MN845892-MN845928.

Detection of the cytokines IL-6, IL-17A, IFN- $\gamma$, and IL-35

Cytokines Human IL-6 (EUA, cat. DY206; R\&D Systems, Minnesota), Human IL-17-A (cat. 900-M84; Peprotech, Cranbury), Human IFN- $\gamma$ (cat. 900-K27; Peprotech, Cranbury), and Human IL-35 (Cat. E-EL-H2443; Elabscience, Wuhan, Hubei, China) were analyzed in the plasma of peripheral blood by Sandwich ELISA kits as the method in compliance with manufacturer's directions. Standard curves were prepared by serial dilutions of the aliquot corresponding to cytokine pattern supplied by the manufacturer. The determination of the optical density of samples and standards was performed using Expert ${ }^{\circledR}$ Plus spectrophotometer (Biochrom, Cambridge, UK).

\section{Data analysis}

Descriptive statistics of the qualitative variables was determined by frequency distribution and quantitative variables by medians and interquartile ranges and mean and standard deviation. Afterward, to analyze the association between the infection situation and personal and clinical characteristics, the Pearson chi-square test was used for categorical variables and Mann-Whitney $U$ test (median) or Student's $t$-test (mean) for continuous variables, both at $95 \%$ confidence intervals and $p$-value $\leq 0.05$. Correlation between cytokines and viral load was estimated by Spearman test (the data did not present a normal distribution), and values of $p<0.05$ were considered as significant.

\section{Results}

\section{Study population}

In study population, $59.2 \%$ were males and the mean age was $45.59 \pm 14.07$ years, men being almost 7 years older than women. There was no statistically significant difference for age and viral load between patients with acute and chronic infection (Table 1).

Among the patients with chronic hepatitis B infection, most of them were classified as inactive carriers (24/29), followed by patients with flare (3/29), chronic HBeAgpositive infection with normal ALT (1/29), and HBeAgnegative chronic hepatitis with elevated ALT (1/29).

\section{HBV DNA detection in plasma \\ and phylogenetic analysis}

All HBV DNA was quantified by real time PCR, the median of the viral load for acute patients was $3.15 \pm 2.46$ $\log _{10} \mathrm{IU}$ of $\mathrm{HBV} \mathrm{DNA} / \mathrm{mL}$, and for chronic patients, it was $2.90 \pm 2.47 \log _{10}$ IU of HBV DNA/mL.

In $69.39 \%$ (34/49) of samples, it was possible to amplify by conventional PCR the complete gene from the Pre-SS region $(1,200 \mathrm{bp})$. The isolates obtained were mostly of genotype A (28/34), 19 samples of subgenotype A1, and 09 samples of subgenotype A2. One sample was classified as genotype D (1/34) and one as genotype E (1/34). Four were classified as genotype F (4/34), subgenotype F1 (Table 1).

Regarding the distribution of genotypes, it was observed that $70.0 \%$ of the individuals with acute HBV infection belonged to genotype A and $10.0 \%$ to genotype F. The chronic profile was the one with the highest genotype diversity, $48.3 \%$ of the samples belong to genotype A, $3.4 \%$ to genotype $\mathrm{D}, 3.4 \%$ to genotype $\mathrm{E}$, and $6.9 \%$ to genotype $\mathrm{F}$. No correlation was found between virus genotypes and cytokine production.

\section{Detection of the cytokines IL-6, IL-17A, INF- $\gamma$, and IL-35}

The median levels of IFN- $\gamma(p=0.024)$ and IL-17A $(p=0.046)$ were statistically higher in chronic patients compared to acute patients (Table 2). The Figure 1 shows the median levels of IL-6 and IL-35 that were higher in acute patients when compared to the chronic group. The IL$17 \mathrm{~A}$ and INF- $\gamma$ showed $p$-value $<0.005$ when acute and chronic groups were compared.

A negative correlation between viral load and IL-17A ( $p=0.031)$ was observed through the Spearman correlation coefficient (Table 3 and Fig. 2).

\section{Discussion}

Hepatitis B has a wide spectrum of manifestations, ranging from an acute self-limiting disease with resolution for cure, until hepatitis chronic with progress to cirrhosis and HCC $(36,39)$. Although a number of studies have demonstrated data about cytokines, viral load, or genotypes in patients with hepatitis B, few studies compared these data between acute and chronic hepatitis $\mathrm{B}$ infections. In this study, a comparison of the production of IL-35, IL-6, IL$17 \mathrm{~A}$, and IFN- $\gamma$ between acute and chronic infection was performed, since it is already well documented in the literature that these cytokines are increased in individuals infected with HBV in relationship to healthy controls.

HBV DNA is an important marker, and all major international guidelines base their treatment decisions on the HBV DNA cutoff points, these treatment decisions based on HBV DNA have been shown to decrease the risk of liver decompensation, development of HCC, and death (17). However, the value of HBV DNA is limited, a study by Wang et al., (53) demonstrated intrahepatic replication despite the suppression of HBV DNA, and the negativity of 
Table 1. Demographic, Epidemiological, Clinical, and Genotypic Characteristics of the Population

\begin{tabular}{|c|c|c|c|c|c|c|c|}
\hline \multirow{2}{*}{$\begin{array}{l}\text { Categorical } \\
\text { variables }\end{array}$} & \multicolumn{2}{|c|}{ Total $(\mathrm{n}=49)$} & \multicolumn{2}{|c|}{$\begin{array}{l}\text { Acute infection } \\
\quad(\mathrm{n}=20)\end{array}$} & \multicolumn{2}{|c|}{$\begin{array}{l}\text { Chronic Infection } \\
\quad(\mathrm{n}=29)\end{array}$} & \multirow{2}{*}{$\begin{array}{c}\text { p-value } \\
\text { Qui-quadrado }\end{array}$} \\
\hline & $\mathrm{n}$ & $\%$ & $\mathrm{n}$ & $\%$ & $\mathrm{n}$ & $\%$ & \\
\hline Gender & & & & & & & 0.621 \\
\hline Female & 20 & 40.8 & 09 & 45.0 & 11 & 37.9 & \\
\hline Male & 29 & 59.2 & 11 & 55.0 & 18 & 62.1 & \\
\hline Genotypes & & & & & & & - \\
\hline A & 28 & 57.1 & 14 & 70.0 & 14 & 48.3 & \\
\hline $\mathrm{D}$ & 01 & 2.0 & 00 & 0.0 & 01 & 3.4 & \\
\hline $\mathrm{E}$ & 01 & 2.0 & 00 & 0.0 & 01 & 3.4 & \\
\hline $\mathrm{F}$ & 04 & 8.2 & 02 & 10.0 & 02 & 6.9 & \\
\hline \multirow[t]{2}{*}{ Did not amplify } & 15 & 30.6 & 04 & 20.0 & 11 & 37.9 & \\
\hline & & & \multicolumn{2}{|c|}{ Acute infection } & \multicolumn{2}{|c|}{ Chronic infection } & \\
\hline Continuous variables & Mean & $S D$ & Mean & $S D$ & Mean & $S D$ & $\mathrm{p}$-value $T$-student \\
\hline \multicolumn{8}{|l|}{ Age (years) } \\
\hline Female & 38.70 & 11.16 & 40.11 & 9.64 & 37.55 & 12.62 & 0.622 \\
\hline Male & 45.59 & 14.07 & 39.91 & 10.47 & 49.06 & 15.10 & 0.090 \\
\hline Viral Load $(\log 10 \mathrm{IU}$ DNA/mL) & 3.37 & 1.70 & 3.48 & 1.76 & 3.29 & 1.68 & 0.714 \\
\hline Continuous variables & Median & $P 25-P 75$ & Median & $P 25-P 75$ & Median & $P 25-P 75$ & $\begin{array}{c}\mathrm{p}-\text { value } \\
\text { Mann-Whitney }\end{array}$ \\
\hline \multicolumn{8}{|l|}{ Age (years) } \\
\hline Female & 35.50 & $32.25-43.75$ & 42.00 & $31.50-46.50$ & 34.00 & $33.00-44.00$ & 0.552 \\
\hline Male & 45.00 & $33.50-56.50$ & 39.00 & $30.00-48.00$ & 46.00 & $38.00-60.25$ & 0.102 \\
\hline Viral load $(\log 10$ IU DNA/mL) & 3.01 & $2.46-3.68$ & 3.15 & $2.46-4.46$ & 2.90 & $2.47-3.57$ & 0.497 \\
\hline
\end{tabular}

$\mathrm{SD}$, standard deviation.

HBV DNA does not mean a cure for HBV infection. A study published by Gao et al., (17) demonstrated that HBV DNA in patients with chronic hepatitis $B$ is related to the level of intrahepatic cccDNA before treatment in $\mathrm{HBeAg}$-positive patients. HBeAg reactive subjects generally have elevated HBV DNA viral load compared to HBeAg nonreactive subjects (20).

In our study, the median of the viral load for acute patients was $3.15 \pm 2.46 \log \mathrm{IU} / \mathrm{mL}$, and for chronic patients, it was $2.90 \pm 2.47 \log \mathrm{IU} / \mathrm{mL}$. These results are in agreement with the current literature that found HBV DNA viral loads within hepatitis $\mathrm{B}$ patients ranged from 1.13 to $8.42 \mathrm{log}$ $\mathrm{IU} / \mathrm{mL}$ and DNA viral load lower relative to the chronic samples; in acute HBV infection, the peak DNA levels were 5.53 and $9.23 \log \mathrm{IU} / \mathrm{mL}$ (8). Nita et al., (38), analyzing a cohort of 564 chronic patients in Brazil, found a median of
$2.35 \log$ copies/mL of HBV DNA, and Sarkar et al. (40) demonstrated a median of viral load of $2.13 \log$ copies $/ \mathrm{mL}$ in acute patients and no significant variation of viral load among different HBV genotypes and subgenotypes. We also found no correlation between viral load and genotypes.

The criteria for assessing correlations in this study were the viral load of all patients in relationship to cytokine production, we found a significant negative correlation between viral load and IL-17A $(p=0.031)$ through Spearman's correlation coefficient.

As we know, HBV is a noncytopathic virus, both HBVrelated liver damage and viral control are immunomediated (5) and IL-17 can directly mediate the inflammatory response in liver cells (56). Therefore, IL-17 could be mediating proinflammatory effects even with a decrease in viral load in individuals infected with HBV.

Table 2. Median Levels of Cytokines in Acute and Chronic Hepatitis B

\begin{tabular}{lccccccc}
\hline & & \multicolumn{2}{c}{ Acute infection } & & \multicolumn{2}{c}{ Chronic infection } & \\
\cline { 3 - 4 } Cytokines & Total $\mathrm{n}$ & Median & $P 25-P 75$ & & Median & $P 25-P 75$ & p-value Mann-Whitney \\
\hline IL-6 & 20 & 0.37 & $0.22-0.58$ & & 0.21 & $0.11-0.66$ & 0.487 \\
IL-17A & 47 & 2.74 & $2.00-2.84$ & & 2.82 & $2.68-2.87$ & 0.046 \\
INF- $\gamma$ & 46 & 3.04 & $2.57-3.17$ & & 3.15 & $3.11-3.20$ & 0.024 \\
IL-35 & 42 & 1.14 & $0.47-1.50$ & & 0.95 & $0.00-1.24$ & 0.287 \\
\hline
\end{tabular}

IL, interleukin. 

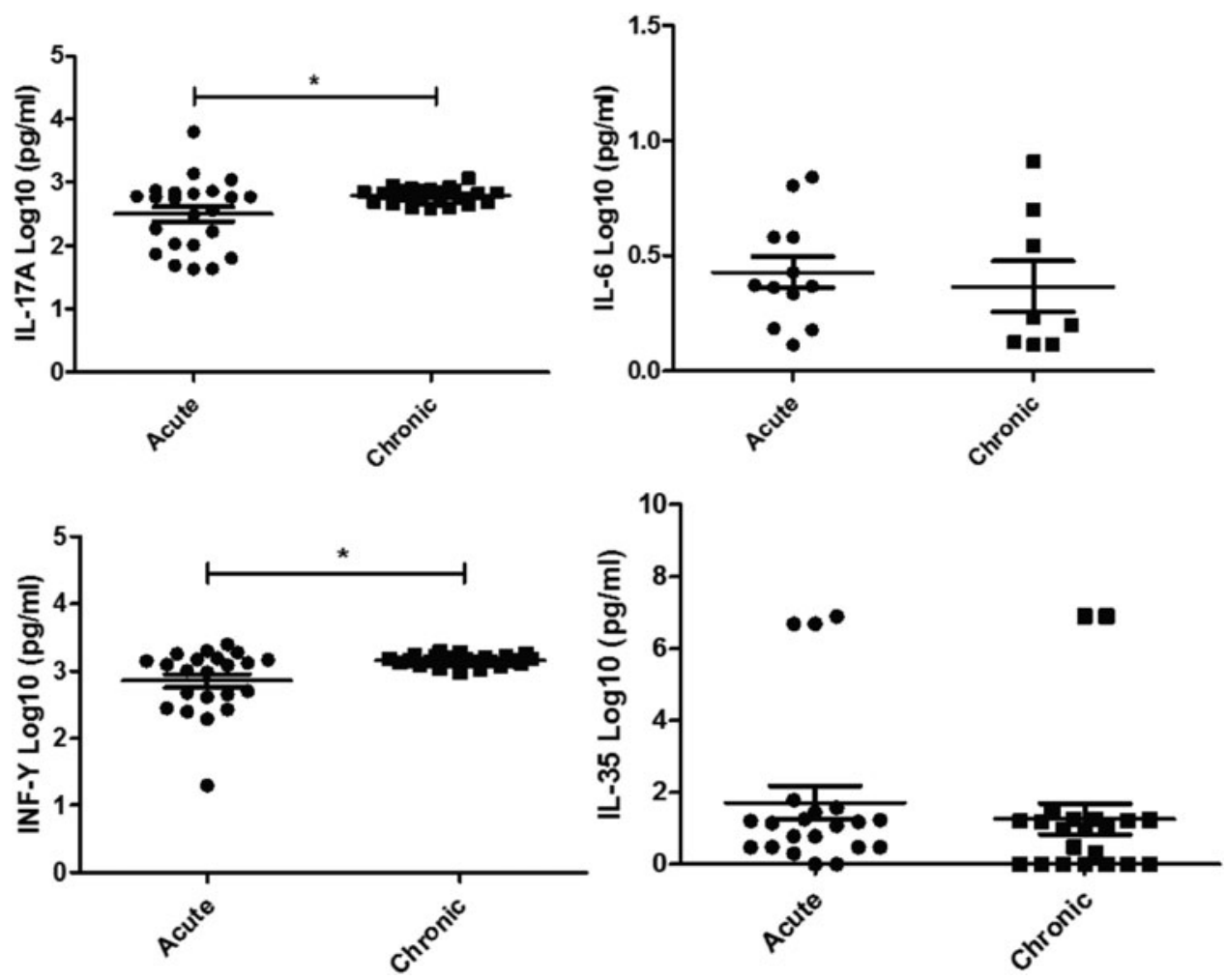

FIG. 1. Comparison of cytokines found in acute and chronic patients by ELISA using the nonparametric Mann-Whitney test. $* p<0.05$. ELISA, enzyme-linked immunosorbent assay; IL, interleukin.

In this study, the isolates obtained were mostly of genotype A (30/37), 19 samples of subgenotype A1 (19/37), and $11(11 / 37)$ samples of subgenotype A2. The genotype A1 has geographical distribution in Africa, Asia, and Brazil, the genotype A2 is most commonly found in Northern Europe and United States. One sample was identified as genotype D, the most prevalent genotype in Africa, Mediterranean region, and India; one sample was identified as genotype $\mathrm{E}$, and this genotype is restricted to West Africa. Curiously, this sample was from an immigrant from Angola. Five samples were classified in the genotype F, subgenotype F1, and this genotype is found in Central and South America $(25,47,50)$. Although, a high diversity of genotypes was found, no correlation was found between genotypes and cytokines.

There are clear differences in adaptive immunity in patients with chronic or resolved HBV infection. HBV-specific $\mathrm{CD}^{+}$and $\mathrm{CD}^{+} \mathrm{T}$ cell responses with a Th1 cytokine production profile are detectable in high blood titers of subjects with a favorable outcome. These Th1 cell responses along with cytotoxic responses are quantitatively stronger

Table 3. Correlation Between Viral Load and Cytokines by Rô de Spearman

\begin{tabular}{lc}
\hline Cytokines & Viral load (p-value) \\
\hline IL-6 & $-0.048(0.840)$ \\
IL-17A & $-0.318(0.031)$ \\
INF- $\gamma$ & $-0.212(0.162)$ \\
IL-35 & $0.046(0.722)$ \\
\hline
\end{tabular}

than those found in patients with chronic infections, which are, in contrast, characterized by weaker or undetectable virus-specific $\mathrm{T}$ cell responses $(9,15,24,45)$.

Some factors inherent to the host can contribute to natural course of the infection. In this study, we found a higher prevalence of males and a higher average age among those who chronified than those with spontaneous resolution. Data from the literature confirm a three to sixfold increase in men's propensity for chronicity, hypothetically explained by the protective effect of estradiol, which induces the production of INF- $\gamma$, aiding in seroconversion to anti-HBs and anti-HBe in acute cases, in addition to its antioxidant effect, in the chronic phase, promoting a more benign course in premenopausal women (44).

Here, IL-35, IL-6, IL-17A, and IFN- $\gamma$ were investigated, and these cytokines are well documented and have a great impact on the clinical outcomes associated with hepatitis B. However, this impact is still not well understood and some cytokines such as IL-6 and IL-35 have a controversial role in HBV infection, which may induce cirrhosis and HCC or eliminate $\mathrm{HBV}$ via inducing humoral and cellular immune response. Cytokines IFN-Y and IL-17A are well described in association with chronic hepatitis, cirrhosis, and HCC via combination with other proinflammatory cytokines.

In our study, the IL-17A was higher in chronic patients compared to the acute cases and showed a negative correlation between viral load and IL-17A. T helper 17 (Th17) cells are significantly raised in chronic HBV-infected patients. Th17 cells initiate immune-mediated pathogenesis and have an important role in the process of HBV-related liver cirrhosis (HBV-LC). The mechanisms underlying this 


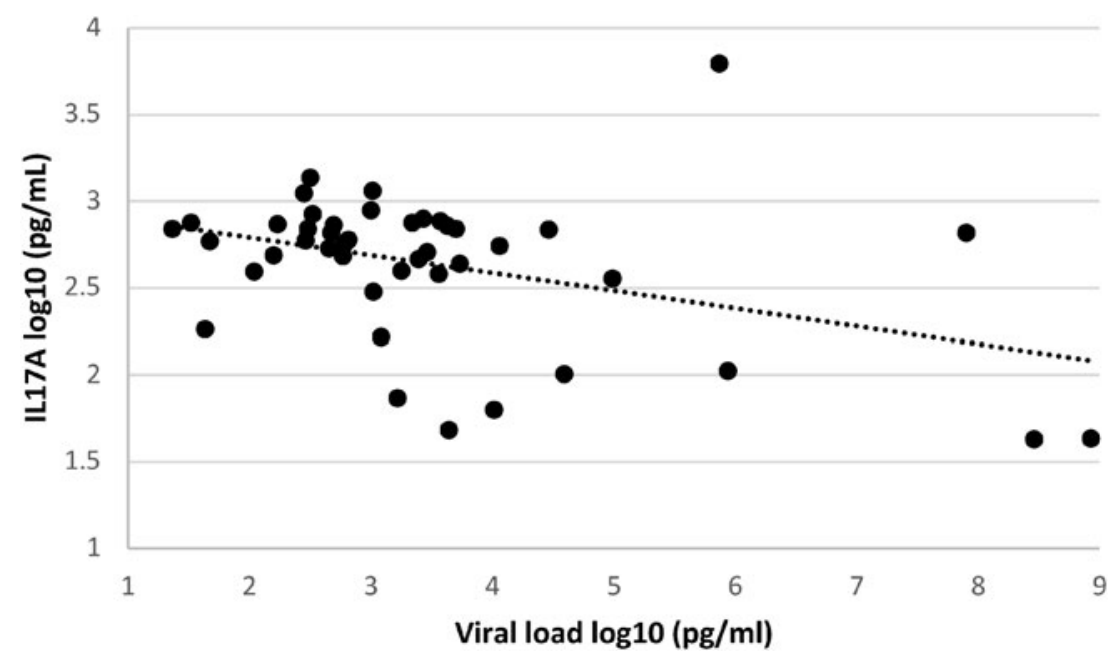

FIG. 2. Negative correlation between viral load and IL-17A through the Spearman correlation coefficient.

process are associated to Th17-secreted cytokines, which include IL-17 (4). IL-17A is upregulated in HBV-mediated chronic inflammation and may be relevant for the development of liver cirrhosis and HCC $(11,14,56)$. IL-17 can also significantly stimulate monocytes and DCs to express IL-17R and produce proinflammatory cytokines such as IL- $1 \beta$, TNF- $\alpha$, IL-6, and so on, which are important for liver damage during hepatitis B progression (59). In addition, IL-17 can directly mediate the inflammatory response in liver cells, and activation of the inflammatory response in liver tissue between hepatic stromal cells promoted abundant TGF- $\beta 1$ expression, resulting in progression to hepatic fibrosis in hepatitis B chronic (56).

A previous study showed that IL-17A expression in the liver tissues of the patients was positively correlated with inflammation grade and fibrosis stage, and positively stained LB suggested that IL-17A drives part in chronic HBV infection (11). The highest IL-17A levels in the serum and liver were observed in LC patients, implying that IL-17A might participate in the pathogenesis and/or progression of liver fibrosis. A study by Elkhawaga et al., (12) showed that serum IL-17A levels were also significantly elevated in chronic patients with hepatitis $\mathrm{C}$ with advanced stages of fibrosis.

In our study, IFN- $\gamma$ was higher in chronic patients compared to the acute ones. INF- $\gamma$ is the only representative of the cytokine class of the INF type II and is produced by a big variety of cells, including NK cells, $\mathrm{CD} 4^{+} \mathrm{LTh} 1$, and $\mathrm{CD} 8^{+} \mathrm{LT}(2)$. This cytokine plays a crucial role in innate and adaptive immunity. For example, IFN- $\gamma$ increases Type I IFN, inflammatory cytokines, and chemokines production, which leads to leukocyte recruitment to the sites of infection, and upregulates FasL expression in CTL (cytotoxic T lymphocytes) and MHC class II and costimulatory molecules on Antigen Presenting Cells (APC), which influences $\mathrm{CD}^{+} \mathrm{T}$ cell responses against pathogens. Also, IFN- $\gamma$ induces IL-12 secretion, which, in turn, increases the cytotoxic activity of $\mathrm{NK}$ cells and drives $\mathrm{CD} 4^{+}$naive $\mathrm{T}$ cells differentiation to the Th1 profile. In this way, IFN- $\gamma$ plays a pivotal role during viral infections (32).

IL-6 and IL-35 levels were higher in acute patients when compared to the chronic group, but without statistical dif- ference. IL-6 is a pleiotropic cytokine with well-known beneficial impacts on the liver. It increases the liver regeneration and protects against an amount of liver-damaging influences such as alcohol and carbon tetrachloride intoxication. Some studies reported that HBV entry was inhibited by up to $90 \%$ when cells were pretreated with IL-6, resulting in a substantial reduction of cccDNA and HBsAg secretion; besides it, IL-6 inhibits HBV entry through the downregulation of the viral entry receptor NTCP (7) and has been demonstrated that IL-6 protects hepatocytes from T cellmediated damage (21).

Curiously, our findings for IL-35 differ from a study, in which serum levels of IL-35 were significantly increased in the cirrhotic process (43) and regulated the functions of viral-specific Tregs and $\mathrm{CD}^{+} \mathrm{T}$ cells during chronic HBV infection, which might contribute to immunotolerance and viral persistence $(33,42)$. However, a recent study showed that IL-35 play contradictory roles in controlling viral persistence and inhibiting inflammatory responses and have an immunosuppressive function in chronic hepatitis $\mathrm{C}$ virus (HCV) infection (33) and another study suggests that influenza A virus infection can induce IL-35 expression and IL-35 can activate the IFN pathway and may have a potential antiviral activity (54). These findings suggest that further studies are necessary for a better understanding of the complex regulatory mechanisms of the host antiviral response related to IL-35 during $\mathrm{HBV}$ infection.

\section{Conclusions}

IL-17A and IFN- $\gamma$, higher in chronic patients, can be modulating proinflammatory effects and inducing hepatocellular damage. Therefore, these cytokines could be considered therapeutic targets for the adjuvant treatment of chronic hepatitis and for the prevention of liver tissue injury in HBV-infected subjects. IL-6 and IL-35, higher in acute patients, can be involved in viral elimination and protection against chronicity. In acute cases, only genotypes $\mathrm{A}$ and $\mathrm{F}$ were found, and the viral load was higher than chronic cases. These results can contribute to the understanding of the complex regulatory mechanisms of the host's antiviral 
response related to cytokine production and spontaneous clearance or persistence of HBV infection.

\section{Ethical Approval}

FIOCRUZ Ethics Committee (number: CAE 06109812.4 .0000.5248).

\section{Acknowledgments}

We thank the Clinic of Viral Hepatitis of Oswaldo Cruz Foundation and Paulo Sergio Fonseca Souza, Biologist project manager of the Clinic of Viral Hepatitis of Oswaldo Cruz.

\section{Author Disclosure Statement}

No competing financial interests exist.

\section{Funding Information}

This study was financed by the Coordenação de Aperfeiçoamento de Pessoal de Nível Superior-Brasil (CAPES)_Finance Code 001, Fundação de Amparo à Pesquisa do Estado do Rio de Janeiro (FAPERJ) and Oswaldo Cruz Institute who approved the project and funded the research with scholarship and grants.

\section{References}

1. Abara WE, Qaseem A, Schillie S, et al. Hepatitis B vaccination, screening, and linkage to care: best practice advice from the American College of Physicians and the Centers for Disease Control and Prevention. Ann Intern Med 2017;167:794-804.

2. Abbas AK, Lichtman AH, and Pillai S. Cytokines. Cell Mol Immunol 2007;251-282.

3. Anisimova M, and Gascuel O. Approximate likelihoodratio test for branches: a fast, accurate, and powerful alternative. Syst Biol 2006;55:539-552.

4. Bao S, Zheng J, and Shi G. The role of T helper 17 cells in the pathogenesis of hepatitis B virus-related liver cirrhosis (Review). Mol Med Rep 2017;16:3713-3719.

5. Bertoletti A, and Ferrari C. Innate and adaptive immune responses in chronic hepatitis B virus infections: towards restoration of immune control of viral infection. Gut 012; 61:1754-1764.

6. Bertoletti A, and Gehring AJ. The immune response during hepatitis B virus infection. J Gen Virol 2006;87(Pt 6): 1439-1449.

7. Bouezzedine F, Fardel O, and Gripon P. Interleukin 6 inhibits HBV entry through NTCP down regulation. Virology 2015;481:34-42.

8. Butler EK, Gersch J, McNamara A, et al. Hepatitis B virus serum DNA andRNA levels in nucleos(t)ide analog-treated or untreated patients during chronic and acute infection. Hepatology 2018;68:2106-2117.

9. Chang JJ, Wightman F, Bartholomeusz A, et al. Reduced hepatitis B virus (HBV)-specific CD4+ T-cell responses in human immunodeficiency virus type 1-HBV-coinfected individuals receiving $\mathrm{HBV}$-active antiretroviral therapy. J Virol 2005;79:3038-3051.

10. Cho HJ, Kim SS, Namb JS, et al. Higher serum interleukin-17A levels as a potential biomarker for predicting early disease progression in patients with hepatitis
B virusassociated advanced hepatocellular carcinoma treated with sorafenib. Cytokine 2017;95:118-125.

11. Du WJ, Zhen JH, Zeng ZQ, et al. Expression of interleukin17 associated with disease progression and liver fibrosis with hepatitis B virus infection: IL-17 in HBV infection. Diagn Pathol 2013;8:40.

12. Elkhawaga AA, Hosni A, Zaky DZ, et al. Association of Treg and TH17 cytokines with HCV pathogenesis and liver pathology. Egypt J Immunol 2019;26:55-63.

13. European Association for the Study of the Liver. EASL clinical practice guidelines: management of chronic hepatitis B virus infection. J Hepatol 2017;67:370-398.

14. Fenoglio D, Bernuzzi F, Battaglia F, et al. Th17 and regulatory $\mathrm{T}$ lymphocytes in primary biliary cirrhosis and systemic sclerosis as models of autoimmune fibrotic diseases. Autoimmun Rev 2012;12:300-304.

15. Ferrari C, Penna A, Bertoletti A, et al. Cellular immune response to hepatitis $\mathrm{B}$ virus-encoded antigens in acute and chronic hepatitis B virus infection. J Immunol 1990;145: 3442-3449.

16. Fields BN, Knipe DM, and Howley PM. Fields Virology 2013; 6th. Philadelphia: Lippincott Williams \& Wilkins, 2456.

17. Gao Y, Li Y, Meng Q, et al. Serum hepatitis B virus DNA, RNA, and HBsAg: which correlated better with intrahepatic covalently closed circular DNA before and after nucleos(t)ide analogue treatment? J Clin Microbiol 2017; 55:2972-2982.

18. Gomes SA, and Niel CMG. Hepatites virais. In: Santos NSO, Romanos MTV, Wigg MD, eds. Introdução à Virologia Humana. 2 Ed. Rio de Janeiro: Guanabara Koogan, 2008.

19. Guindon S, Dufayard JF, Lefort V, et al. New algorithms and methods to estimate maximum-likelihood phylogenies: assessing the performance of PhyML 3.0. Syst Biol 2010; 59:307-321.

20. Höner Z, Siederdissen C, Maasoumy B, et al. New viral biomarkers for Hepatitis B: are we able to change practice?. J Viral Hepat 2018;25:1226-1235.

21. Hosel M, Quasdorff M, Wiegmann K, et al. Not interferon, but interleukin- 6 controls early gene expression in hepatitis B virus infection. Hepatology 2009;50:1773-1782.

22. Huang Z, Velkinburgh JC, Ni B, et al. Pivotal roles of the interleukin-23/T helper 17 cell axis in hepatitis B. Liver Int 2012;32:894-901.

23. ICTV - International Committee on taxonomy of viruses 2012. [2020.02.07] http://ictvonline.org/ (accessed February 7, 2020).

24. Jung MC, Hartmann B, Gerlach JT, et al. Virus-specific lymphokine production differs quantitatively but not qualitatively in acute and chronic hepatitis B infection. Virology 1999;261:165-172.

25. Lago BV, do Espirito-Santo MP, Costa VD, et al. Genetic diversity of the hepatitis B virus subgenotypes in Brazil. Viruses 2019;11:860.

26. Lamontagne RJ, Bagga S, and Bouchard MJ. Hepatitis B virus molecular biology and pathogenesis. Hepatoma Res 2016;2:163-186.

27. Lampe E, Mello FCA, Espírito-Santo MPdo, et al. Nationwide overview of the distribution of hepatitis $\mathrm{B}$ virus genotypes in Brazil: a 1000-sample multicentre study. J Gen Virol 2017;98:1389-1398.

28. Li H, Yan L, Shi Y, et al. Hepatitis B virus infection: overview. Adv Exp Med Biol 2020;1179:1-16. 
29. Lian JQ, Yang XF, Zhao RR, et al. Expression profiles of circulating cytokines, chemokines and immune cells in patients with hepatitis B virus infection. Hepat Mon 2014; 14:e18892.

30. Liaw YF, and Tsai SL. Pathogenesis and clinical significance of spontaneous exacerbation and remissions in chronic HBV infection. Viral Hepat Ver 1997;3:143-154.

31. Lin CL, and Kao JH. Natural history of acute and chronic hepatitis B: the role of HBV genotypes and mutants. Best Pract Res Clin Gastroenterol 2017;31:249-255.

32. Lin F-C, and Young H A. Interferons: success in anti-viral immunotherapy. Cytokine Growth Factor Rev 2014;25: 369-376.

33. Liu S, Zhang Q, Shao X, et al. An immunosuppressive function of interleukin-35 in chronic hepatitis $\mathrm{C}$ virus infection. Int Immunopharmacol 2017;50:87-94.

34. Lopes TGSL, and Schinoni MI. Aspectos gerais da hepatite B. R Ci Med Biol 2011;10:337-344.

35. Manno M, Cammà $\mathrm{C}$, Schepis $\mathrm{F}$, et al. Natural history of chronic HBV carriers in northern Italy: morbidity and mortality after 30 years. Gastroenterology 2004;127:756-763.

36. Mcmahon, BJ. Natural history of chronic hepatitis B-clinical implications. Medscape J Med 2008;10:91.

37. Mello FC, Souto FJ, Nabuco LC, et al. Hepatitis B virus genotypes circulating in Brazil: molecular characterization of genotype F isolates. BMC Microbiol 2007;7:103.

38. Nita ME, Gaburo N, Jr., Cheinquer H, et al. Patterns of viral load in chronic hepatitis B patients in Brazil and their association with ALT levels and HBeAg status. Ann Hepatol 2009;8:339-345.

39. Pungpapong S, Kim RW, and Poterucha JJ. Natural history of hepatitis B virus infection: an update for clinicians. Mayo Clin Proc 2007;82:967-975.

40. Sarkar N, Pal A, Das D, et al. Virological characteristics of acute hepatitis B in Eastern India: critical differences with chronic infection. PLoS One 2015;10:e0141741.

41. Schaefer S. Hepatitis B virus taxonomy and hepatitis B virus genotypes. World J Gastroenterol 2007;13:14-21.

42. Shao X, Ma J, Jia S, et al. Interleukin-35 suppresses antiviral immune response in chronic hepatitis B virus infection. Front Cell Infect Microbiol 2017;7:472.

43. Shi M, Wei J, Dong J, et al. Function of interleukin-17 and -35 in the blood of patients with hepatitis B-related liver cirrhosis. Mol Med Rep 2015;11:121-126.

44. Shimizu I, Kohno N, Tamaki K, et al. Female hepatology: favorable role of estrogen in chronic liver disease with hepatitis B virus infection. World J Gastroenterol 2007;13: 4295-4305.

45. Sobao Y, Tomiyama H, Sugi K, et al. The role of hepatitis $B$ virus-specific memory CD8 T cells in the control of viral replication. J Hepatol 2002;36:105-115.

46. Stein LL, and Loomba R. Drug targets in hepatitis B virus infection. Infect Disord Drug Targets 2009;9:105-116.
47. Sunbul M. Hepatitis B virus genotypes: global distribution and clinical importance. World J Gastroenterol 2014;20: 5427-5434.

48. Tang LSY, Covert E, Wilson E, et al. Chronic hepatitis B infection-a review. JAMA 2018;319:1802-1813.

49. Terrault NA, Lok ASF, McMahon BJ, et al. Update on prevention, diagnosis, and treatment of chronic hepatitis $\mathrm{B}$ : AASLD 2018 Hepatitis B Guidance. Clin Liver Dis (Hoboken) 2018;12:33-34.

50. Valaydon ZS, and Locarnini SA. The virological aspects of hepatitis B. Best Pract Res Clin Gastroenterol 2017;31: 257-264.

51. Valente F, Lago BV, Castro CA, et al. Epidemiology and molecular characterization of hepatitis B virus in Luanda, Angola. Mem Inst Oswaldo Cruz 2010;105:970-977.

52. Villar LM, Cruz HM, Barbosa JR, et al. Update on hepatitis B and C virus diagnosis. World J Virol 2015;4:323-342.

53. Wang J, Shen T, Huang X, et al. Serum hepatitis B virus RNA is encapsidated pregenome RNA that may be associated with persistence of viral infection and rebound. J Hepatol 2016;65:700-710.

54. Wang L, Zhu S, Xu G, et al. Gene expression and antiviral activity of interleukin-35 in response to influenza A virus infection. J Biol Chem 2016;291:16863-16876.

55. WHO - World Health Organization 2017. GLOBAL HEPATITIS REPORT, 2017. [2020.02.07] https://www .who.int/hepatitis/publications/global-hepatitis-report2017/ en/ (accessed February 7, 2020).

56. Wu W, Li J, Chen F, et al. Circulating Th17 cells frequency is associated with the disease progression in HBV infected patients. J Gastroenterol Hepatol 2010;25:750-757.

57. Xia Y, and Protzer U. Control of hepatitis B virus by cytokines. Viruses 2017;9:18.

58. Yang J, Xi Q, Deng R, et al. Identification of interspecies recombination among hepadnaviruses infecting crossspecies hosts. J Med Virol 2007;79:1741-1750.

59. Zhang JY, Zhang Z, Lin F, et al. Interleukin-17-producing CD4(+) $\mathrm{T}$ cells increase with severity of liver damage in patients with chronic hepatitis B. Hepatology 2010;51: 81-91.

Address correspondence to: Dr. Vanessa Salete de Paula Laboratory of Molecular Virology Oswaldo Cruz Institute Oswaldo Cruz Foundation 4365, Brasil Avenue Manguinhos

Rio de Janeiro 21040-360 Brazil

E-mail:vdepaula@ioc.fiocruz.br 